\title{
Tip30 controls differentiation of murine mammary luminal progenitor to estrogen receptor-positive luminal cell through regulating FoxA1 expression
}

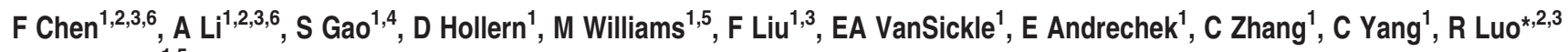 \\ and $\mathrm{H} \mathrm{XiaO}{ }^{*, 1,5}$
}

Estrogen receptor-alpha positive $\left(\mathrm{ER}^{+}\right)$breast cancers comprise the majority of human breast cancers, but molecular mechanisms underlying this subtype of breast cancers remain poorly understood. Here, we show that $\mathrm{ER}^{+}$mammary luminal tumors arising in Tip30 ${ }^{-/}$MMTV-Neu mice exhibited increased enrichment of luminal progenitor gene signature. Deletion of the Tip30 gene increased proportion of mammary stem and progenitor cell populations, and raised susceptibility to $\mathrm{ER}^{+}$ mammary luminal tumors in female Balb/c mice. Moreover, $\mathrm{Tip}^{-1-}$ luminal progenitors displayed increases in propensity to differentiate to mature $\mathrm{ER}^{+}$luminal cells and FoxA1 expression. Knockdown of FoxA1 expression in Tip30 ${ }^{-1-}$ progenitors by shRNA specific for FoxA1 reduced their differentiation toward ER ${ }^{+}$mature luminal cells. Taken together, our results suggest that TIP30 is a key regulator for maintaining $\mathrm{ER}^{+}$and $\mathrm{ER}^{-}$luminal pools in the mammary luminal lineage, and loss of it promotes expansion of $\mathrm{ER}^{+}$luminal progenitors and mature cells and $\mathrm{ER}^{+}$mammary tumorigenesis.

Cell Death and Disease (2014) 5, e1242; doi:10.1038/cddis.2014.224; published online 22 May 2014

Subject Category: Cancer

Estrogen receptor-alpha $(E R \alpha)$ has important roles in the development and carcinogenesis of mammary glands. ${ }^{1,2}$ Approximately $75 \%$ of human breast cancers are immunostained positive for $\mathrm{ER} \alpha\left(\mathrm{ER}^{+}\right)$at the times of diagnosis, most of which are positive staining for progesterone receptors $\left(\mathrm{PR}^{+}\right)$. In the past decades, substantial progression has been achieved in the diagnosis and treatment of this subtype of breast cancer; however, the cell of origin and underlying mechanisms of $\mathrm{ER}^{+} / \mathrm{PR}^{+}$breast cancer remains poorly understood. $^{3}$

Deciphering the regulation of mammary luminal cell differentiation may divulge important clues for identifying the cell of origin for $\mathrm{ER}^{+}$breast cancers. The mammary epithelium in an adult mammary gland is composed of two lineages of cells: luminal and myoepithelial cells. A small number of mammary cells have been identified as mammary gland stem cells (MaSCs), which can give rise to mature epithelium of either the luminal or myoepithelial lineage through a series of lineage-restricted intermediates. ${ }^{4-6}$ Multilineage progenitors are at an intermediate position in the hierarchy and capable of dividing to luminal-restricted progenitors and myoepithelial-restricted progenitors. The luminal-restricted progenitors are able to differentiate into $\mathrm{ER}^{+}$and ER ${ }^{-}$luminal cells, whereas myoepithelial-restricted progenitors are able to produce ER ${ }^{-}$myoepithelial cells. ${ }^{5,7}$ Most of luminal progenitors in the mammary gland are evidently $\mathrm{ER}^{-}$, but a small population of $\mathrm{ER}^{+}$luminal progenitors has been identified. ${ }^{8-10}$ Several cellular factors have been demonstrated to regulate various aspects of developmental hierarchy of cell differentiation using genetically-engineered mouse models. For example, MMTV-Wnt1 mice exhibited an expansion of the MaSCs pool and development of both $\mathrm{ER}^{+} / \mathrm{PR}^{+}$and $\mathrm{ER}^{-} / \mathrm{PR}^{-}$types of mammary tumors, whereas MMTV-Neu mice showed no expansion of MaSCs and generated $\mathrm{ER}^{-} / \mathrm{PR}^{-}$mammary tumors. ${ }^{4,11,12}$ Subsequent studies have suggested that MMTV-Neu tumors may arise from lobular alveolar progenitors that are functionally similar to $\mathrm{ER}^{-}$luminal progenitors, ${ }^{10,13,14}$ whereas MMTV-Wnt1 tumors originate from ductal progenitors, ${ }^{4,15,16}$ and mammary tumors caused by Brca1 mutations arise from luminal progenitors committed to $\mathrm{ER}^{-}$ luminal cell differentiation. ${ }^{17}$

\footnotetext{
${ }^{1}$ Department of Physiology, Michigan State University, East Lansing, MI, USA; ${ }^{2}$ Cancer Center, Southern Medical University, Guangzhou, China; ${ }^{3}$ Traditional Chinese Medicine-Integrated Hospital, Southern Medical University, Southern Medical University, Guangzhou, China; ${ }^{4}$ Department of Biochemistry and Molecular Biology, Michigan State University, East Lansing, MI, USA and ${ }^{5}$ Cell and Molecular Biology Program, Michigan State University, East Lansing, MI, USA

${ }^{*}$ Corresponding author: R Luo, Cancer Center, Traditional Chinese Medicine-Integrated Hospital, Southern Medical University, Guangzhou, Guangdong 510315, China. Tel: + 86206165 0001; Fax: + 86206165 0009; E-mail: luorc01@ 163.com

or H Xiao, Department of Physiology, Michigan State University, 3193 Biomedical and Physical Sciences Building, East Lansing, MI 48824-3320, USA. Tel: + 517884 5127; Fax: + 517355 5125; E-mail: xiaoh@msu.edu

${ }^{6}$ These authors contributed equally to this work.

Keywords: TIP30; Mammary progenitor; breast cancer; ER $\alpha$; FoxA1

Abbreviation: Tip30, 30 kDa HIV-1Tat interacting protein; FoxA1, forkhead box protein; MMTV, mammary tumor virus; Neu, murine epidermal growth factor receptor 2; Wint1, Wingless-type MMTV integration site family member 1; EGFR, epidermal growth factor receptor 1; CD24, cluster of differentiation 24; CD49f, cluster of differentiation 49f; PI3K, phosphatidylinositol-4,5-bisphosphate 3-kinase; mTOR, mechanistic target of rapamycin

Received 21.1.14; revised 11.4.14; accepted 17.4.14; Edited by G Raschellà
} 
TIP30, also known as HTATIP2 or CC3,${ }^{18,19}$ is implicated in the pathogenesis of several types of human cancers including breast cancer. ${ }^{20-22}$ There has been a body of evidence showing that it acts as a tumor suppressor involved in the regulation of multiple cellular processes including cell proliferation and apoptosis through influencing ER-mediated transcription, EGFR signaling and nuclear importins in cells. ${ }^{23-26}$ Particularly, loss of Tip30 in mice was found to cause ductal hyperplasia in mammary glands early in life and extensive mammary hyperplasia with age. ${ }^{27}$ In addition, deletion of the Tip30 gene in MMTV-Neu mouse was shown to result in increased $\mathrm{ER}^{+}$luminal cells in the preneoplastic mammary glands and development of $\mathrm{ER}^{+} / \mathrm{PR}^{-}$mammary tumors. ${ }^{24}$ Despite these observations, the role of Tip30 in regulation of differentiation of mammary stem cells (MaSCs)/ progenitors remains unknown. Here, we describe that loss of Tip30 not only promoted expansion of mammary stem and luminal progenitor cells in mammary gland, but also influenced luminal progenitor cells fate via upregulation of FoxA1, leading to an increased subpopulation of mature $E R^{+}$ luminal cells, which may contribute to $\mathrm{ER}^{+}$mammary tumor development.

\section{Results}

Tip30 ${ }^{-/-}$MMTV-Neu tumors show enrichment of luminal progenitor gene signature and cluster with a subtype of human HER2 ${ }^{+}$breast cancer. We previously reported that Tip30 loss promotes development of $\mathrm{ER}^{+}$luminal carcinomas in MMTV-Neu mouse model. ${ }^{24}$ To further explore the role of Tip30 in $\mathrm{ER}^{+}$luminal carcinomas development, we arrayed mammary tumors arising in MMTV-Neu and Tip30 ${ }^{-/-}$ MMTV-Neu mice. Unsupervised hierarchical clustering revealed a significant difference in Tip $30^{-/-}$MMTV-Neu tumors as compared with control MMTV-Neu tumors (Figure 1a). Consistent with the previous report, ${ }^{24}$ EGFR and Ras signaling were further enhanced in Tip30 ${ }^{-/-}$ MMTV-Neu tumors (Figure 1b). The gene expression profiles of the tumors were then clustered with human breast cancer profiles that had been annotated using intrinsic clustering. ${ }^{28}$ In agreement with previous studies, ${ }^{29}$ MMTV$\mathrm{Neu}$ tumors do not cluster well with human HER2 ${ }^{+}$tumors. We noted that Tip30 $0^{-1-}$ MMTV-Neu tumors clustered most closely with human luminal $A$ and $B$ types of breast cancers and secondly with human $\mathrm{HER} 2^{+}$tumors (Supplementary Figure $1 \mathrm{~A}$ ), indicating that Tip $30^{-/-}$MMTV-Neu tumors are mimicking human luminal types of breast cancers. We also used publicly available gene expression data to analyze for a role of these identified differentially expressing genes in overall patient survival. We observed that low levels of major histocompatibility complex (MHC) in $\mathrm{HER}^{+}$breast cancer samples were associated with poor survival relative to $\mathrm{HER}^{+}$breast cancer samples with high levels of $\mathrm{MHC}$ (Supplementary Figure 1B). Intriguingly, when the gene signatures of mouse luminal progenitor, mature luminal and stem/basal cells ${ }^{30}$ in Tip30 $0^{-/-}$MMTV-Neu tumors versus MMTV-Neu tumors were compared, Tip30 loss resulted in increased enrichment of luminal progenitor gene signature (Figure 1c, $P=0.0147$; FDR $q=0.0217$ ), whereas without significantly affecting enrichment of mature luminal and

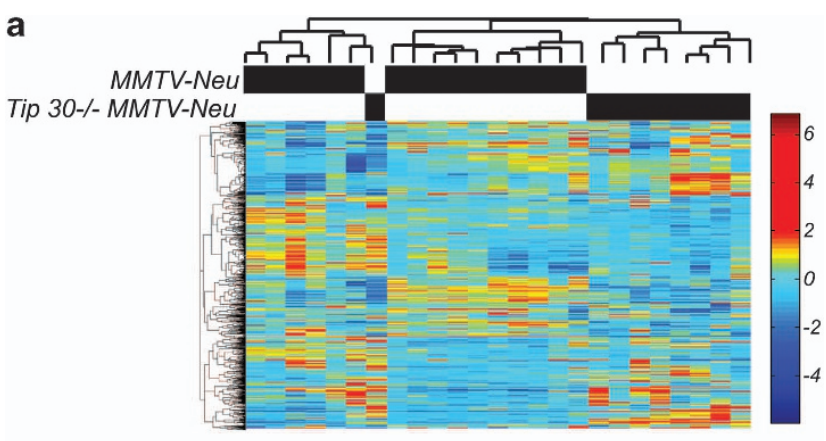

b

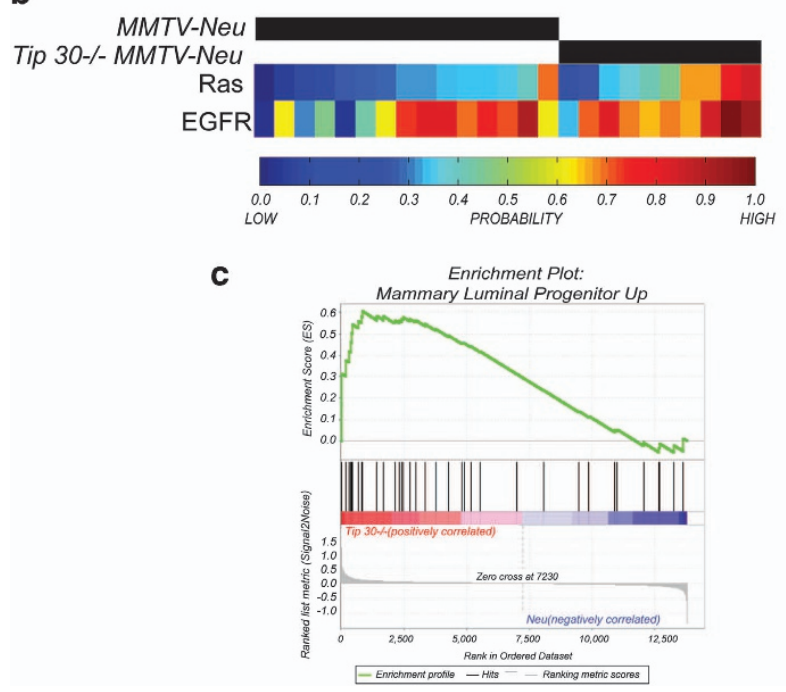

Figure1 Comparison of gene expression profiles of Tip30 $0^{-/} /$MMTV-Neu tumors with MMTV-Neu tumors. (a) Unsupervised hierarchical clustering illustrating the relationships between Tip30 $0^{+/+}$MMTV-Neu tumors $(n=15)$ and Tip30 MMTV-Neu tumors $(n=9)$. (b) Gene signature predictions for Ras signal pathway activation and EGFR signal pathway activation in Tip30 $0^{+/+}$MMTV-Neu tumors $(n=15)$ and Tip30 $0^{-1-}$ MMTV-Neu tumors $(n=9)$. (c) GSEA enrichment plot of Tip30-1- MMTV-Neu tumors by utilizing luminal progenitor gene signature. Values above 0 indicate increased enrichment of the gene signature, whereas values below 0 indicate a loss in enrichment. Vertical black lines represent individual genes in the luminal progenitor gene set that contribute to the enrichment score. Genes illustrated by the gray bar are ranked by fold change differences between Tip30 $30^{-1-}$ MMTV-Neu tumors and Tip $30^{+/+}$MMTV-Neu tumors. The heatmap below the black vertical lines illustrate the direction of fold change where genes in red have the highest positive fold change and genes in the blue region have the most negative fold change

stem/basal cell signatures (data not shown). This result indicates that Tip30 is a potential regulator controlling proliferation and differentiation of luminal progenitors in the mammary gland.

Loss of Tip30 increases susceptibility to spontaneous $\mathrm{ER}^{+} / \mathbf{P R}^{+}$luminal subtype of mammary tumors. To further study the role of Tip30 in mammary development and tumorigenesis, we monitored a cohort of Tip30 ${ }^{-1-}$ and Tip30 ${ }^{+/+}$Balb/c female mice for spontaneous tumor development for 18 months. Kaplan-Meier plot analysis revealed that $28.6 \%$ of Tip $30^{-/-}$mice spontaneously developed mammary tumors with an average latency of 16 months, whereas Tip30 $0^{+/+}$mice did not (Figure 2a, 
a
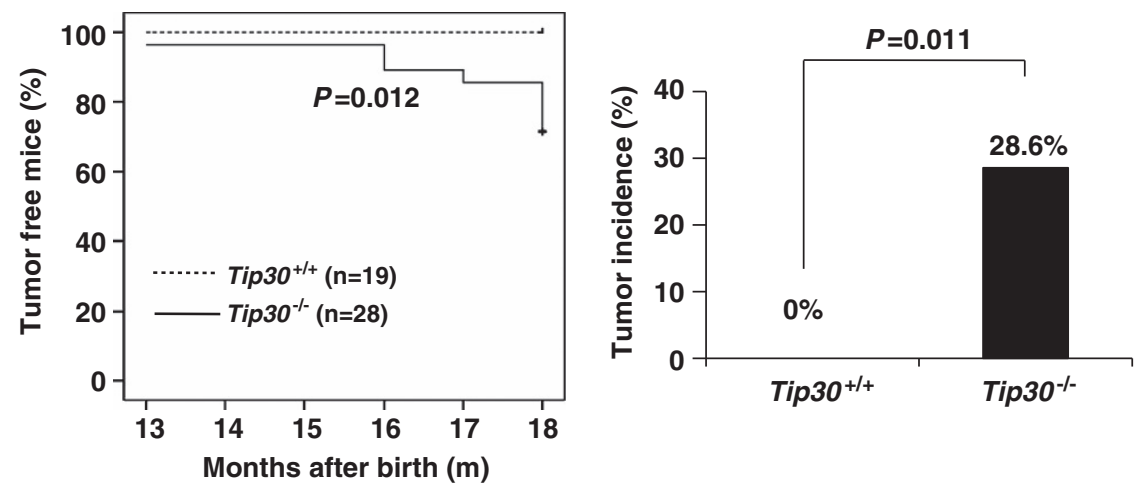

b

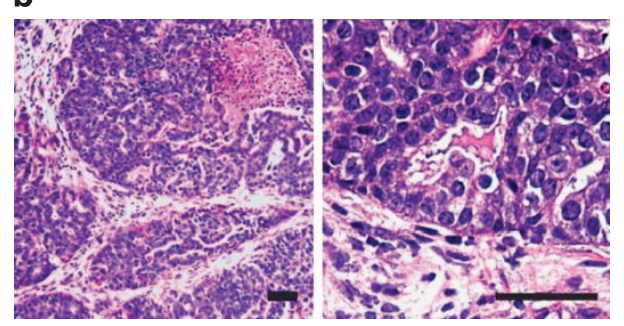

c

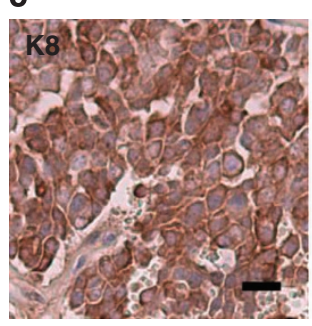

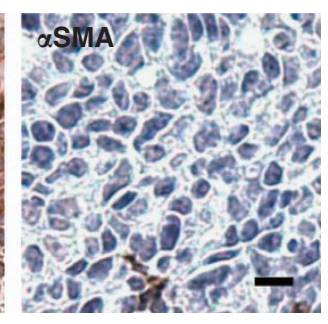

d
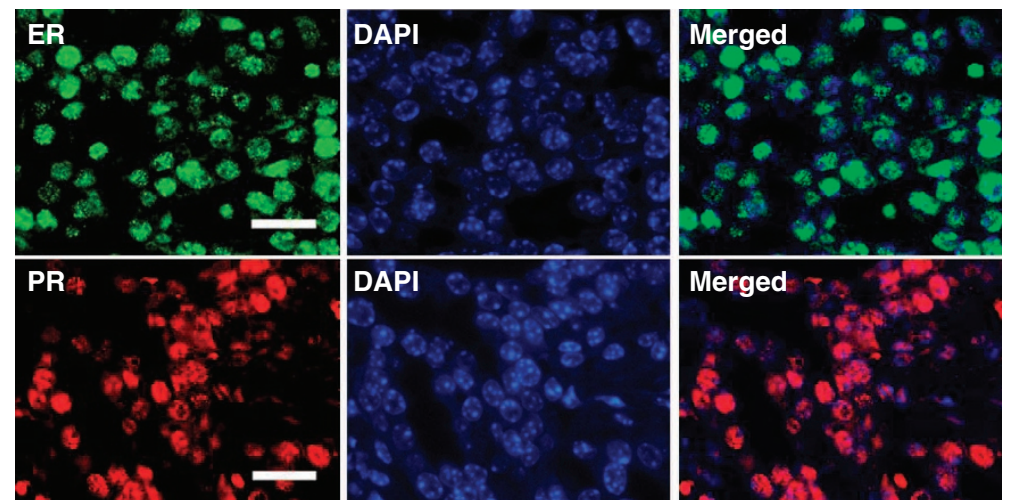

Figure 2 Tip30 $0^{-/-}$balb/c mice developed mammary tumors. (a) Kaplan-Meier curves showing palpable tumors of Tip30 $0^{-/-}(n=28)$ and Tip30 until 18 months. Histogram showing incidence of mammary tumor in Tip30 ${ }^{-/-}$and Tip $30^{+/+}$mice. (b) Representative images of H\&E stained sections of mammary tumors in Tip30 $30^{-1-}$ mice. Scale bar: $20 \mu \mathrm{m}$. (c) Representative images of immunostaining section for CK8 and $\alpha$ SMA in mammary tumor of Tip30 $0^{-1-}$ mice. Scale bar: $10 \mu \mathrm{m}$. (d) Representative immunofluorescent staining of ER $\alpha$ and PRs in mammary tumors of Tip30 $0^{-1-}$ mice. Scale bar: $20 \mu \mathrm{m}$

$P=0.012)$. Histological analysis showed that all tumors arising from Tip $30^{-/-}$female mice are moderately differentiated infiltrating ductal carcinomas composing of atypical epithelial cells arranged as ducts, glands, nests and micropapillary patterns (Figure 2b). Immunohistochemical staining of the mammary tumors arising in Tip $30^{-/-}$mice demonstrated that almost all of them were K8-positive, but $\alpha$ SMA-negative, ER-positive and PR-positive (Figures $2 \mathrm{c}$ and d). These results suggest that Tip30 deletion increases susceptibility to the development of $\mathrm{ER}^{+} / \mathrm{PR}^{+}$luminal subtype of mammary tumors in Balb/c mice.

Tip30 deletion promotes expansion of stem cell and progenitor cell subpopulations. To investigate whether Tip30 loss influences the stem/progenitor cell compartment and epithelial differentiation in the mammary gland, we first used an in vitro system, in which primary MaSCs are propagated on non-adherent substrata to form mammospheres. The number of mammospheres in the mediums reflects the number of stem cells that were plated in the system, whereas the size of mammospheres is a reflection of progenitor cell proliferation. ${ }^{31}$ Mammary cells from 5-month-old Tip30 ${ }^{-/-}$and $\mathrm{Tip}^{-0^{+/+}}$mouse mammary glands were isolated and subsequently plated in the mammosphere medium. Compared with Tip30 $0^{+/+}$mammary cells, Tip30 ${ }^{-/-}$mammary cells displayed an increased number of mammoshperes (Figure 3a, $P<0.05$ ). The average size of mammospheres formed by ${\text { Tip } 30^{-/-}}^{-}$ mammary epithelial cells was larger than those formed by Tip30 $0^{+/+}$mammary cells $(P<0.05)$. Moreover, colonyforming cell assay by seeding mammary cells at low-cell density in matrigel substrata revealed that mammary cells isolated from Tip $30^{-1-}$ mammary glands generated more colonies with larger size in diameter as compared with mammary cells from Tip $30^{+} /{ }^{+}$mammary glands (Figure $3 \mathrm{~b}$, $P<0.05)$. These results indicated that Tip30 deletion 
a
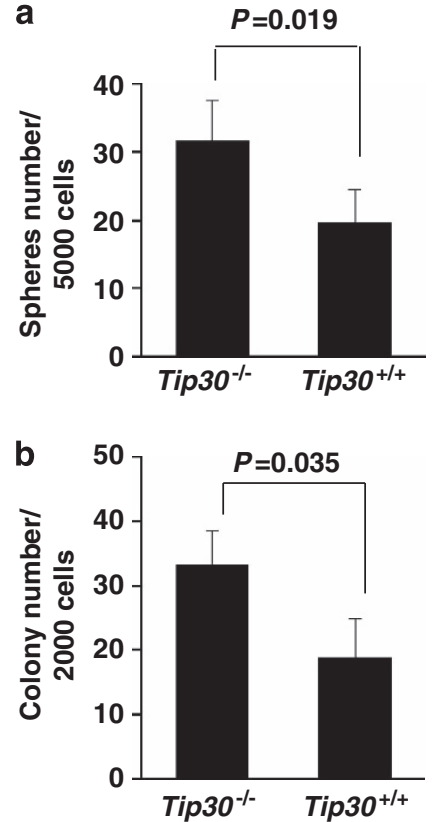
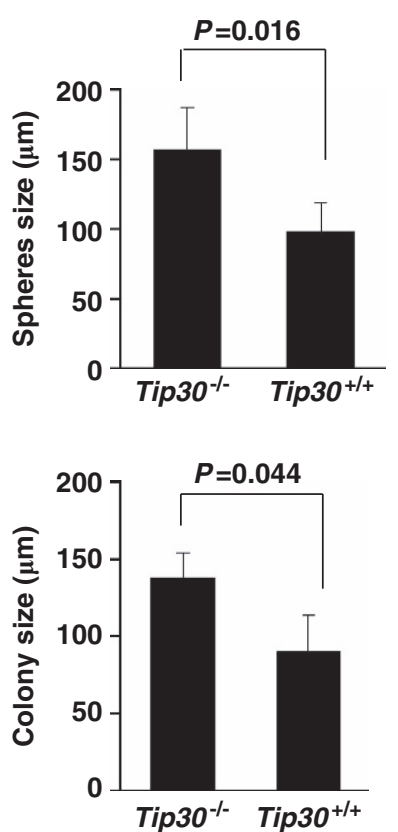

Figure 3 Tip30 deletion enhanced the mammosphere and colony-forming capacity of mammary cells. (a) Freshly isolated mammary cells from mice at 5 months of age were plated in ultra-low attachment plates (5000 cells per well) with serum-free DMEM/F12 medium supplemented with growth factors. After 10 days in culture, mammosphere's number and size were calculated as shown in histograms. Only mammospheres exceeding $60 \mu \mathrm{m}$ in diameter were counted. Error bars represent the mean \pm S.E.M. of three mice per group. (b) Freshly isolated mammary cells from mice were plated in Matrigel-coated 48-well plates (2000 cells per well). Colonies were cultured for 9 days and then photographed. The histograms show colony number and size. The results are the mean \pm S.E.M. of three mice per group

promotes expansion of stem cell and progenitor cell subpopulations.

We next used flow cytometric analyses to identify cell populations and define their differentiation hierarchy in mammary glands. MaSCs are enriched in CD24 ${ }^{+}$CD49f $f^{\text {high }}$ population containing mammary repopulating units that are able to generate multilineage outgrowths in vivo, whereas progenitors are enriched in CD24 ${ }^{\text {high }} \mathrm{CD} 49 \mathrm{f}^{+}$population with mammary colony-forming cells that produce discrete colonies of mammary cells. ${ }^{6}$ The mammary glands of 5-month-old virgin wild-type and Tip30 $0^{-/-}$mice were dissected and processed to single-cell suspensions; cells were separated by FACS according to their CD24 and CD49f expression. As shown in Figures $4 a$ and b, CD24 ${ }^{+}$CD49f ${ }^{\text {high }}$ stem cell enriched population was significantly increased by about twofold in mammary epithelium of Tip30 ${ }^{-/-}$mice compared with mammary epithelium of wild-type littermates $(P<0.05)$. Similarly, the $\mathrm{CD} 24^{\text {high }} \mathrm{CD} 49 \mathrm{f}^{+}$progenitor cell-enriched population of $\mathrm{Tip}^{-1-}$ mammary epithelium was about 3.5-fold higher than that of wild-type mammary epithelium (Figures $4 \mathrm{a}$ and b, $P<0.01$ ). These results suggest that Tip30 controls expansion of both MaSCs and progenitor cells.

Loss of Tip30 promotes luminal progenitor cells to ER ${ }^{+}$ luminal cells differentiation. Previous studies have defined

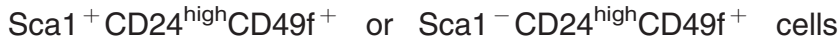
as $\mathrm{ER}^{+}$or $\mathrm{ER}^{-}$luminal progenitor cells, respectively. ${ }^{32,33}$

a
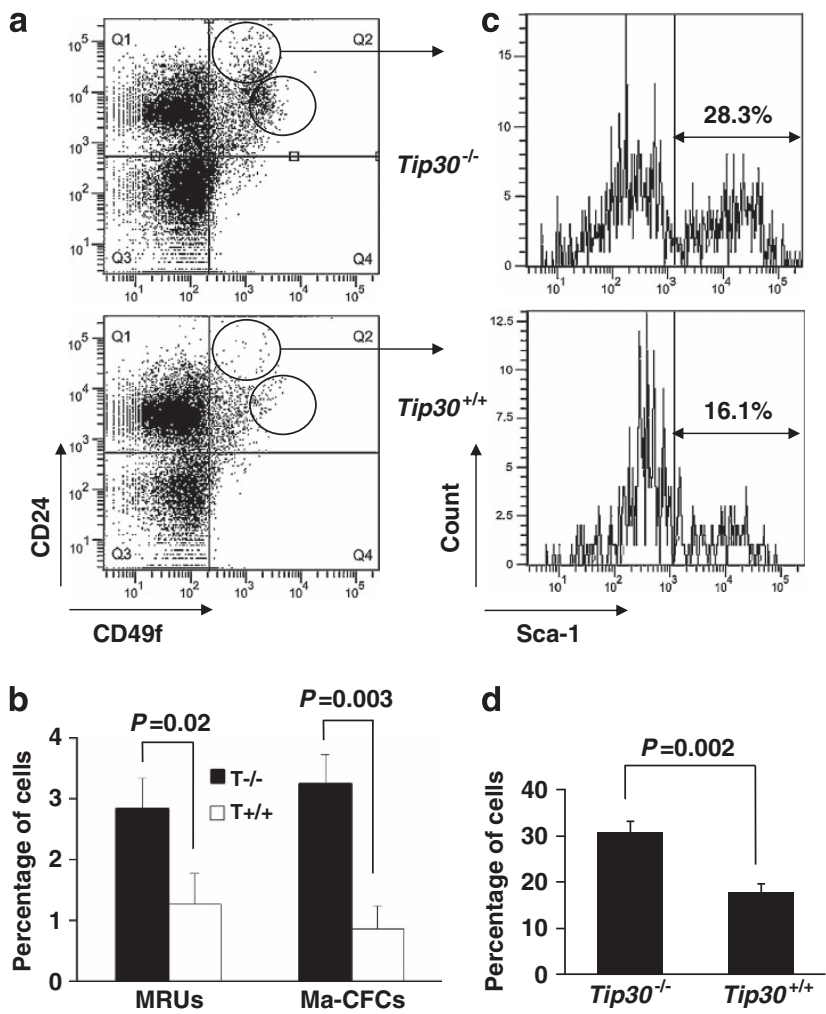

Figure 4 Tip30 deletion promotes expansion of the MaSC-enriched and progenitor-enriched subpopulation in mammary glands by flow cytometry. (a) Flow cytometry dot plots of primary mouse mammary cells isolated from 5-month-old virgin mice and stained with antibodies for CD24 and CD49f. (b) The histograms show the percentage of mammary repopulating units and mammary colony-forming cells of subpopulation in mammary cells. Error bars represent the mean \pm S.E.M. of three mice per group. (c) $\mathrm{CD} 24^{\text {high }} \mathrm{CD} 49 \mathrm{f}^{+}$subpopulation was further analyzed by Sca1. Sca1 ${ }^{+} \mathrm{CD}_{24} 4^{\text {high }} \mathrm{CD} 49 f^{+}$or $\mathrm{Sca} 1{ }^{-} \mathrm{CD} 24^{\text {high }} \mathrm{CD} 49 \mathrm{f}^{+}$cells sorted from Tip30 ${ }^{-1-}$ female mice $(n=6)$ were further analyzed by immunonocytochemistry with anti-ER $\alpha$ antibodies. About $77 \%$ of Sca $1{ }^{+}$CD24 ${ }^{\text {high }}$ CD $49 f{ }^{+}$and $\sim 26 \%$ Sca1 ${ }^{-}$CD24highCD49f ${ }^{+}$cells were stained positive for ER $\alpha$. (d) The histogram shows percentage of $\mathrm{Sca} 1^{+}$cells in $\mathrm{CD} 24^{\text {high }} \mathrm{CD} 49 \mathrm{f}^{+}$subpopulation. Error bars represent the mean \pm S.E.M. of three mice per group

To determine whether $\mathrm{ER}^{+}$or $\mathrm{ER}^{-}$luminal progenitors were increased in Tip30 ${ }^{-/-}$mammary epithelium, we used Sca1 expression as a sorting marker to separate cells between $\mathrm{ER}^{+}$and $\mathrm{ER}^{-}$luminal progenitors in the $\mathrm{CD} 24^{\text {high }} \mathrm{CD} 49 \mathrm{f}^{+}$ population. As shown in Figures $4 \mathrm{c}$ and $\mathrm{d}$, Sca1 ${ }^{+}$luminal progenitor cells were significantly increased in Tip30 $0^{-1-}$ mammary glands compared with that in Tip30 ${ }^{+/+}$mammary glands $(P<0.05)$. Consistent with the previous observations on $\mathrm{ER} \alpha$ expression in Sca1 ${ }^{+}$luminal progenitor cells, ${ }^{32,33}$ we also observed that the majority of $(\sim 77 \%)$ of Sca1 ${ }^{+}$ $\mathrm{CD}_{24}{ }^{\text {high }} \mathrm{CD}_{49 f}{ }^{+}$luminal cells and only a minor portion ( $\sim 26 \%)$ of Sca1 ${ }^{-}$CD24 ${ }^{\text {high }}$ CD49f ${ }^{+}$luminal cells were ER ${ }^{+}$ cells. To test whether these progenitor population committed to $\mathrm{ER}^{+}$cell differentiation fate, $\mathrm{CD} 244^{\text {high }} \mathrm{CD} 49 f^{+}$populations from ${\text { Tip } 30^{-/-} \text {and Tip30 }}^{+/+}$mammary glands were sorted out and subjected to in vitro colony-forming cell assay. Indeed, colonies formed by Tip30 ${ }^{-/-}$progenitor cells had a significantly higher percentage of $\mathrm{ER}^{+}$cells compared with those formed by Tip $30^{+/+}$progenitors (Figures $5 \mathrm{a}$ and b, $P<0.05)$. However, percentage of $\mathrm{PR}^{+}$cells in colonies 
a
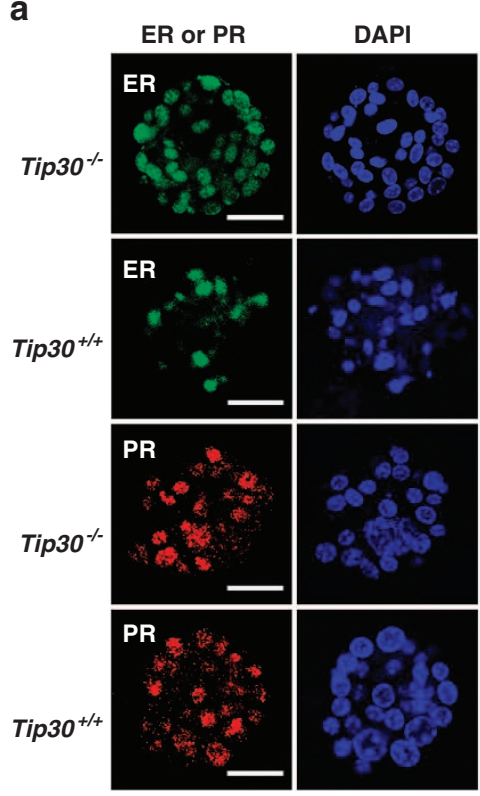

b

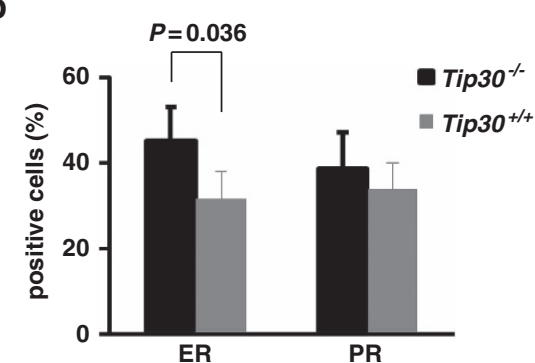

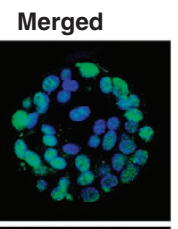

C ER or P
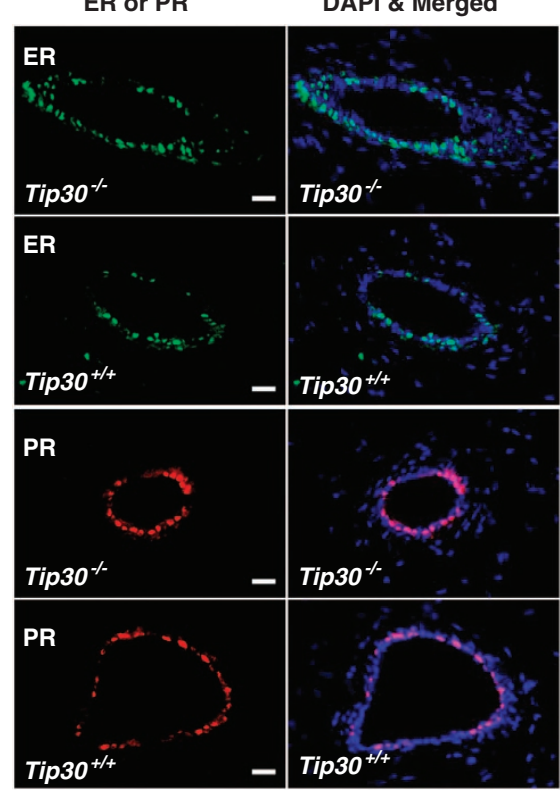

d

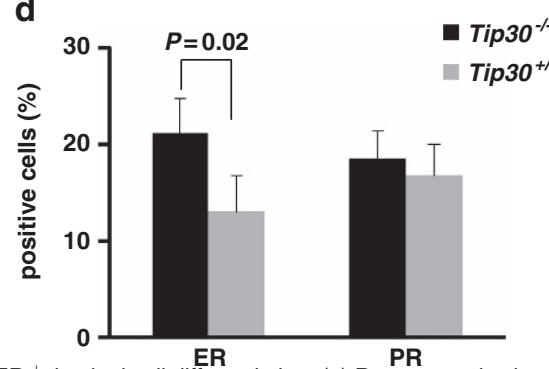

Figure 5 Tip30 deletion predisposed mammary luminal progenitors to commitment of $\mathrm{ER}^{+}$luminal cell differentiation. (a) Representative immunofluorescent staining of $\mathrm{ER} \alpha$ and PR in colonies formed by progenitor cells from Tip $30^{-/-}$and Tip $30^{+/+}$mammary gland. Mammary epithelial cells isolated from 5-month-old virgin mice were processed to single-cell suspensions and stained with CD24 and CD49f. Progenitor cell-enriched population $\left(\mathrm{CD} 24^{\text {high }} \mathrm{CD}_{49 f}{ }^{+}\right.$) was sorted out and plated in Matrigel-coated 48-well plates. After cultured for 9 days, colonies were Immuno stained for ER $\alpha$ and PR-A. Scale bar: $50 \mu \mathrm{m}$. (b) The histogram shows the percentage of ER $\alpha$-positive and PR-A-positive cells in the colonies. Error bars represent the mean \pm S.E.M. of three mice per group. (c) Representative immunofluorescent staining of ER $\alpha$ and PR-A in mammary glands from 5-month-old Tip30 $0^{-1-}$ and Tip30 $0^{+/+}$mice. Scale bar: $20 \mu \mathrm{m}$. (d) The histogram shows the percentage of ER $\alpha$-positive and PR-A-positive cells in mammary glands. The bar graphs denote the mean \pm S.E.M. of three animals per group. Scale bar: $20 \mu \mathrm{m}$

formed by $\mathrm{Tip}^{-1-}$ progenitors was slightly, but not significantly increased when compared with Tip30 $30^{+/+}$ progenitors. Consistent with these observations, we found that the number of $\mathrm{ER}^{+}$cells was significantly increased in Tip $30^{-/-}$mammary glands as compared with Tip $30^{+/+}$ mammary glands, whereas $\mathrm{PR}^{+}$cells were slightly, but not significantly, increased (Figures $5 \mathrm{c}$ and $\mathrm{d}$ ). As suggested by previous studies, ${ }^{24,34,35}$ statistically insignificant increase in $\mathrm{PR}^{+}$cells observed in Tip30 ${ }^{-/-}$mammary glands might be due to PR proteins being rapidly turned over in cells. ${ }^{24}$ Taken together, these results indicated that loss of Tip30 promotes luminal progenitor cells to $\mathrm{ER}^{+}$mature luminal cell differentiation.

Regulation of luminal progenitor cell fate by Tip30 is mediated by FoxA1. Transcription factors Gata-3 and FoxA1 as well as several components in Notch, Hedgehog and Wnt mediated signaling pathways are critical in the regulation of differentiation of MaSCs to the luminal cell lineage in both humans and mice. ${ }^{36,37}$ To test whether expression of these factors in mammary glands is influenced by Tip30 loss, quantitative RT-PCR analysis was performed to measure mRNA levels of Notch1-4, iHh, sHh, Wnt1, Gata-3 and FoxA1 in wild-type and Tip $30^{-/}$mammary glands. We found the mRNA level of FoxA1 was markedly elevated in Tip30 ${ }^{-/-}$mammary gland compared with Tip $30^{+/+}$, whereas mRNA level of Notch1-4, iHh, sHh, Wnt1 or Gata3 was not significantly changed (Figure 6a). Western blot analysis of FoxA1 protein levels in wild-type and Tip30 ${ }^{-/-}$ mammary glands further confirmed increased FoxA1 expression in Tip30 $30^{-1-}$ mammary glands (Figures $6 \mathrm{~b}$ and $\mathrm{c}$ ). Importantly, knockdown of FoxA1 expression significantly reduced proportion of $\mathrm{ER}^{+}$cells in colonies formed by Tip30 ${ }^{-/-}$mammary stem/progenitor cells (Figures $6 \mathrm{~d}-\mathrm{f}$, $P<0.05)$. In agreement with the role of Tip30 in regulation of EGFR/PI3K signaling, FoxA1 expression in Tip30 ${ }^{-/-}$ mammary epithelial cells was significantly reduced after the cells were treated with LY294002, a specific PI3K kinase inhibitor or NVP-BEZ235, a PI3K/mTOR dual kinase inhibitor (Supplementary Data). Taken together, these results 
a

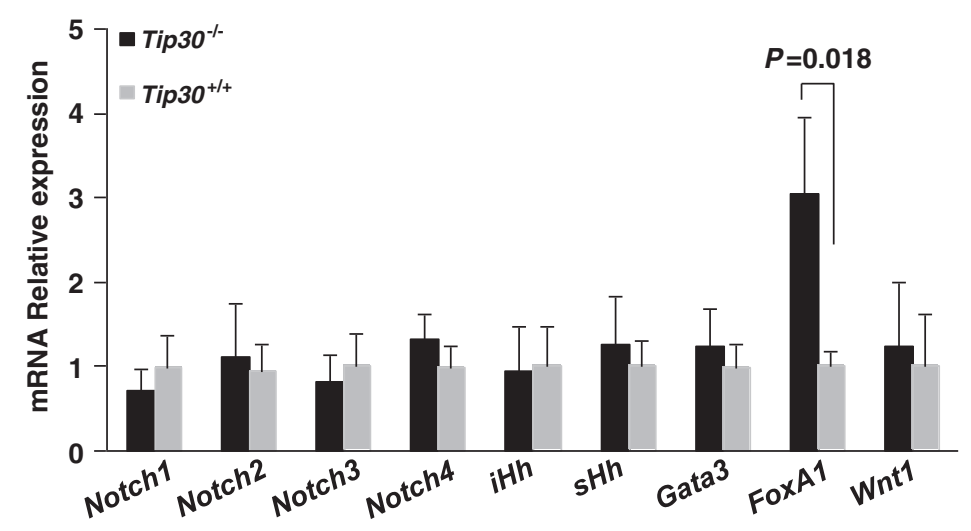

b

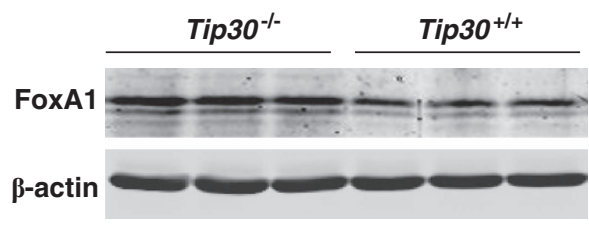

d

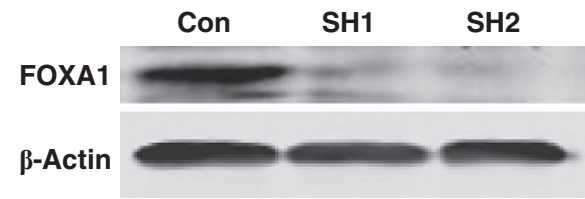

e

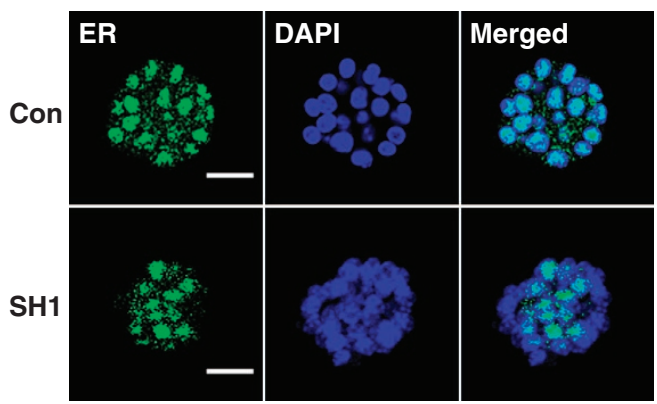

C

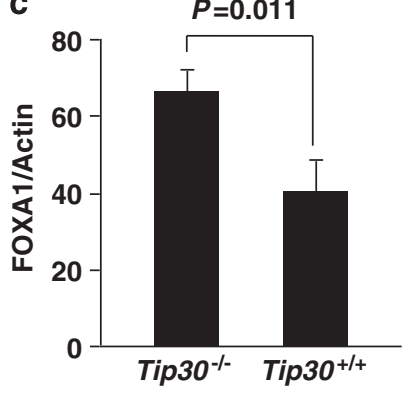

f

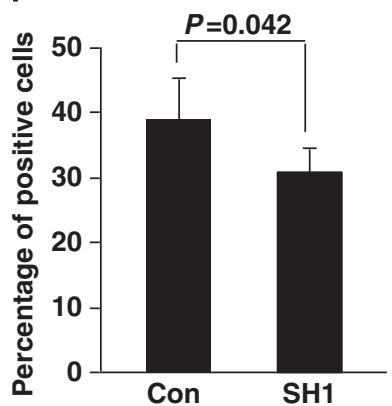

Figure 6 Tip30 deletion regulated progenitor cell fate through the upregulation of FoxA1 level. (a) The relative mRNA levels of genes implicated in regulating mammary cell fate decisions. The RNA were extracted from Tip30 ${ }^{-/-}$and Tip $30^{+/+}$mammary glands of 5-month-old mice and quantified with qRT-PCR. The data are normalized to endogenous control and expressed as mean \pm S.D. from triplicates of a representative experiment. (b) Western blot analysis of FoxA1 protein level in Tip $30^{-/-}$and Tip30 ${ }^{+/+}$mammary glands. (c) The graph shows the FoxA1 levels expressed as the percentages of $\beta$-actin in Tip $30^{-/-}$and Tip $30^{+/+}$mammary glands. The data were mean \pm S.E.M. of three mice per group. (d) Western blot analysis of FoxA1 in Tip30 ${ }^{-1-}$ mammary epithelial cells infected with scramble shRNA-CON, FoxA1-SH1 or FoxA1-SH2 lentivirus. (e) Representative immunofluorescent staining of ER $\alpha$ in the same Tip30 ${ }^{-1-}$ cells infected by control or FoxA1-SH1 lentivirus. Scale bar: $50 \mu \mathrm{m}$. (f) The graph shows the percentage of ER $\alpha$ positive cells in colonies formed by the same Tip30 ${ }^{-1-}$ cells with shRNA-control or FoxA1 knockdown. The results are the mean \pm S.E.M. of three mice per group

suggest that loss of Tip30 predisposes luminal progenitor cells to the commitment of $\mathrm{ER}^{+}$cells differentiation, in part, through an increase in FoxA1 expression.

\section{Discussion}

Elucidating the regulation of mammary cell differentiation hierarchy may lead to the identification of novel factors in the regulation of initiation and progression of various subtypes of breast cancer. Our present data demonstrated that loss of Tip30 in the mammary epithelium results in increased proportion of stem/progenitor cells in murine mammary epithelium and higher propensity of differentiation of luminal progenitors to $\mathrm{ER}^{+}$mature luminal cells both in vivo and in ex vivo. The effect of Tip30 loss on the propensity of cell differentiation to $\mathrm{ER}^{+}$mature luminal cells was likely 
mediated by the transcription factor FoxA1. Thus, our study uncovers a critical role for Tip30 in the maintenance of the normal differentiation of luminal progenitors. In addition, we show that Tip30 deletion promotes spontaneous development of $\mathrm{ER}^{+} \mathrm{PR}^{+}$luminal types of mammary tumors in aged mice.

The present observations of FoxA1 effect on the luminal progenitor differentiation are in agreement with recent findings that FoxA1 is a key regulator in controlling expression of luminal and basal genes in $\mathrm{ER}^{+}$and $\mathrm{ER}^{-}$breast cancer cells. ${ }^{36,38,39}$ FoXA1 has been shown to be required not only for both $E R \alpha$ expression and transcriptional activity, but also for ductal lineage expansion. ${ }^{38,39}$ Moreover, FoxA1 expression has been shown to positively correlate with $\mathrm{ER}^{+} / \mathrm{PR}^{+}$ luminal breast carcinomas. ${ }^{40}$ Using gene expression profiling and gene set enrichment analysis on breast cancer cell lines and breast cancer specimens, reducing FoxA1 expression has been demonstrated to cause a partial shift from luminal to basal gene signatures and basal cancer phenotypes. ${ }^{38}$ Our data are not inconsistent with these previous findings, but rather add further insight into FoxA1 function by suggesting a regulatory pathway mediated by FoxA1 and Tip30 in events controlling the expansion of $\mathrm{ER}^{+}$luminal cells and $\mathrm{ER}^{+}$ mammary luminal tumor development. In support of this hypothesis, our results demonstrate that loss of Tip30 increases the number of Sca $1^{+} \mathrm{CD} 24^{\text {high }} \mathrm{CD} 49 f^{+}$luminal progenitor that has been shown to be ER $\alpha$-positive, ${ }^{32}$ suggesting that Tip30 regulates luminal progenitor cell fate. In addition, we previously reported that Tip30 acts in both nucleus and cytosol of breast cells to repress $\mathrm{ER} \alpha$-mediated transcription of c-Myc gene ${ }^{23}$ as well as EGFR/PI3K signaling. ${ }^{24,25}$ We also show here that inhibition of PI3K/Akt signaling reduced FoxA1 expression in Tip $30^{-/-}$mammary epithelial cells (Supplementary Figure 2). Hence, it is possible that Tip30 loss enhances EGFR/PI3K signaling, leading to increased FoxA1 expression, which in turn promotes expression of $\mathrm{ER} \alpha$ and differentiation of luminal progenitors to $\mathrm{ER}^{+}$ mature luminal cells. Further understanding of this regulatory pathway may contribute to the understanding of molecular mechanisms of normal mammary gland development and $\mathrm{ER}^{+}$breast carcinogenesis.

$\mathrm{ER}^{+} / \mathrm{PR}^{+}$cells comprise about $7-10 \%$ of the luminal epithelial cell population in the normal mature mammary gland, which are rarely proliferative and generally growtharrested by inhibitory factors. ${ }^{41,42}$ Evidently, the majority of human breast cancers at the time of diagnosis were $\mathrm{ER}^{+}$ ductal carcinomas containing proliferative $\mathrm{ER}^{+}$cancer cells. Moreover, clustered $\mathrm{ER}^{+}$proliferating cells were frequently detected in ductal hypoplasia and ductal carcinoma in situ, which are significantly associated with human $\mathrm{ER}^{+}$breast cancer risk. ${ }^{43}$ It has been proposed that loss of such inhibitory factors may instigate carcinogenesis of $\mathrm{ER}^{+}$breast cancers. ${ }^{44,45}$ Given the observations that loss of Tip30 resulted in mammary hyperplasia in female mice of various genetic backgrounds ${ }^{27}$ and increased expression of luminal progenitor gene signature in $\mathrm{ER}^{+}$mammary tumors arising in MMTVNeu mice, we speculate that Tip30 is one of the inhibitory factors in the suppression of differentiation and proliferation of $\mathrm{ER}^{+}$luminal cells. Loss of Tip30 may result in expansion of $\mathrm{ER}^{+}$luminal progenitor and mature luminal cells, which provides more cell targets for subsequent oncogenic events.
Nonetheless, the present work has not provided any direct evidence supporting aberrantly increased ER + progenitors as the cell of origin for $\mathrm{ER}^{+}$luminal tumors. Thus, further studies will be needed to determine the expanded $\mathrm{ER}^{+}$ luminal progenitors in Tip30 ${ }^{-/-}$mammary glands are the cell of origin for $\mathrm{ER}^{+}$luminal tumors.

In summary, we present the first evidence that Tip30 is a key factor regulating luminal progenitor differentiation by controlling FoxA1 expression. Loss of Tip30 increases susceptibility to $\mathrm{ER}^{+}$mammary tumorigenesis. However, whether $\mathrm{ER}^{+}$luminal progenitor is the targeting cell for $\mathrm{ER}^{+}$ mammary tumorigenesis remains undetermined. Future studies on determination of the cell of origin for $\mathrm{ER}^{+}$luminal breast cancers may provide further insight to the understanding of the pathogenesis of $\mathrm{ER}^{+}$breast cancers. Moreover, identification of the oncogenic pathways that are activated by impaired Tip30 function may prove to be useful in the development of new preventive and therapeutic strategies for $\mathrm{ER}^{+}$breast cancers.

\section{Materials and Methods}

Animal studies. Tip $30^{-/-}$Balb/c mice were obtained by backcrossing Balb/c mice with Tip $30^{-1-}$ C57BL/6 mice seven generations as described previously. ${ }^{46}$ All mice were housed in Animal Facility at Michigan State University. Animal protocols used for this study were approved by Michigan State University IACUC Committee.

Histopathology. Mammary glands and other tissues were removed, fixed in $4 \%$ paraformaldehyde solution and then paraffin-embedded. Sections were stained with $\mathrm{H} \& \mathrm{E}$ and examined by two trained investigators and a pathologist who read slides blind to experimental detail. Fresh mammary tissues were frozen with liquid nitrogen after being rinsed with PBS and stored at $-80^{\circ} \mathrm{C}$ for western blot assay.

Immunohistochemistry and immunofluorescence. Immunohistochemistry and immunofluorescence for paraffin-embedded tissues were carried out as described previously. ${ }^{24}$ Primary antibodies against $\alpha$-SMA (clone E184, 1:50; Millipore, Billerica, MA, USA), CK8 (ks8.7, 1:50; Santa Cruz Biotechnology, Dallas, TX, USA), ER $\alpha$ (MC-20, 1:50; Santa Cruz Biotechnology) or PR-A (hPRa7, 1:50; Labvision, Fremont, CA, USA) were used. Alexa-488- or Alexa594-conjugated secondary antibody (1:200; Molecular Probes, Carlsbad, CA, USA) and 4', 6-diamidino-2-phenylindole for immunofluorescence were used. Immunofluorescence staining of in vitro colonies was as described previously. ${ }^{24}$ Briefly, colonies were extracted from matrigel by using PBS-EDTA and then spun to glass slides with a Cytospin4 centrifuge (Thermo Scientific, Kalamazoo, MI, USA). The colonies were fixed with $4 \%$ paraformaldehyde, followed by the immunofluorescence staining procedures. Slides were analyzed by confocal laser scanning microscopy (Carl Zeiss, Oberkochen, Germany).

Mammary cell preparation. Mammary glands from 5-month-old virgin female Balb/c mice were chopped and the finely minced tissue was transferred to a digestion mix consisting of serum-free DMEM/F12 (Gibco, Grand Island, NY, USA) containing 0.3 Wünsch units $/ \mathrm{ml}$ collagenase (Roche, Branford, CT, USA) and $1.5 \mathrm{mg} / \mathrm{ml}$ trypsin (Gibco) and then processed to single cells, as previously described. $^{47}$

Mammosphere assays. Single-cell suspensions were grown (5000 cells/ well) in 96-well Ultra Low Attachment plates (Corning, NY, USA) with serum-free DMEM/F12 medium (Gibco) containing $20 \mathrm{ng} / \mathrm{ml}$ EGF, $20 \mathrm{ng} / \mathrm{ml} \mathrm{bFGF,} 5 \mathrm{mg} / \mathrm{ml}$ insulin, $2 \%$ B27 and $4 \mu \mathrm{g} / \mathrm{ml}$ heparin (Sigma, St. Louis, MO, USA) for 10 days in $37^{\circ} \mathrm{C}, 5 \% \mathrm{CO}_{2}$ incubator. Mammospheres were imaged under microscopy and then calculated for the number and diameter from five randomly selected fields per sample at identical magnifications. Only mammospheres exceeding $60 \mu \mathrm{m}$ in diameter were counted.

Colony-forming assay. 96-well plates were coated with $15 \mu \mathrm{l}$ growth factor reduced Matrigel (BD Biosciences, San Jose, CA, USA) per well. Two thousand cells were seeded to a well with 1:1 DMEM/ F12 medium (Invitrogen) containing 
$10 \%$ growth factor reduced Matrigel, 10\% FBS (Gibico), $5 \mu \mathrm{g} / \mathrm{ml}$ insulin (Sigma), $10 \mathrm{ng} / \mathrm{ml}$ choleratoxin (Sigma) and $10 \mathrm{ng} / \mathrm{ml}$ epidermal growth factor (Sigma) and cultured at $37^{\circ} \mathrm{C}$ in $5 \% \mathrm{CO}_{2}$ in an incubator for 10 days. Photomicrographs were taken and the colony number and size were calculated as described in Mammosphere assays.

Flow cytometry. $\mathrm{CD} 45^{+} / \mathrm{TER} 119^{+}$, and $\mathrm{CD} 31^{+}$cells were removed from dissociated cells using the EasySep biotin selection kit (StemCell Technologies, Vancouver, BC, Canada) according to the manufacturer's instructions. Cells were resuspended in HBSS (Invitrogen) with 2\% FBS and incubated with anti-CD24-PE (10 $\mu$ //test, Mouse mammary cell enrichment kit, StemCell Technologies), anti-CD49f- FITC $(10 \mu /$ test, Mouse mammary cell enrichment kit, StemCell Technologies) or anti-Sca1-APC (0.06 $\mu \mathrm{g} /$ test, eBioscience, San Diego, CA, USA) for $30 \mathrm{~min}$ on ice, followed by washing and resuspending in HBSS supplemented with $2 \%$ FBS. Analysis and sorting were performed by using a FACSVantage TurboSort SE (BD Biosciences). The data were analyzed using BD FACS Sortware sorter software. For analysis of $\mathrm{ER} \alpha$ expression in $\mathrm{Sca} 1^{+}$ $\mathrm{CD}_{2}{ }^{\text {high }} \mathrm{CD}_{49 f^{+}}$and $\mathrm{Sca} 1{ }^{-} \mathrm{CD} 24^{\text {high }} \mathrm{CD} 49 \mathrm{f}^{+}$luminal cell populations, sorted cells from Tip $30^{-1-}$ virgin mice $(n=6)$ were collected and allowed to adhere to a collagen coated 96-well plate before fixation and then analyzed by immunocytochemistry with anti- ER $\alpha$ (MC-20, 1:50; Santa Cruz Biotechnology) and inverted microscopy (Nikon Eclipse Ti, Melville, NY, USA).

Real-time reverse transcription-PCR. Total RNA was isolated using the RNeasy mini kit (Qiagen, Germantown, MD, USA). Reverse transcription was performed using SuperScript III reverse transcriptase (Invitrogen) and Oligo(dT) primer (Invitrogen). The relative gene expressions were measured by real-time RT-PCR using the gene-specific primers and IQ SYBR Green Supermix (Bio-Rad, Hercules, CA, USA). The RNA polymerase II (RPII) was the endogenous control for each cDNA sample. Primers used were as follows: Notch1, forward: 5'-ACAACAACGAGTGTGAGTCC-3' , reverse: $5^{\prime}$-ACACGTGGCTCCTGTATATG-3'; Notch2, forward: 5'-TGACTGTTCCCTCACTATGG-3', reverse: 5'-CACGTCTTGC TATTCCTCTG-3'; Notch3, forward: 5'-AGATCAATGAGTGTGCATCC-3, reverse: 5'-GCAGACTCCATGACTACAGG-3'; Notch4, forward: 5'-GAGGACCTGGTTGAA GAATTGATC-3', reverse: 5'-TGCAGTTTTTCCCCTTTTATCC-3'; iHh, forward: $5^{\prime}$-CGTGCATTGCTCTGTCAAGT-3', reverse: $5^{\prime}$-CTCGATGACCTGGAAAGCTC-3'; sHh, forward: $5^{\prime}$-CCTCTCCTGCTATGCTCCTG-3', reverse: $5^{\prime}$-GTGGCGGTTACA AAGCAAAT-3'; Gata-3, forward: 5'-AGCCACATCTCTCCCTTCAG-3', reverse: 5'-AGGGCTCTGCCTCTCTAACC-3'; FoxA1, forward: 5'-CCCTTTCTCCCTTTCA CTCC-3' ${ }^{\prime}$, reverse: $5^{\prime}$-TGGGCCTAACAACAACAACA-3'; Wnt1, forward: $5^{\prime}$-ACAG CAACCACAGTCGTCAG-3', reverse: 5'-GAATCCGTCAACAGGTTCGT-3'.

Western blotting. Protein extraction from mouse mammary glands and primary cells, and western blotting were carried out as previously described. ${ }^{27}$ Primary antibodies for FoxA1 (H-120, 1:500; Santa Cruz Biotechnology), pAkt (193H12, 1:1000; Cell Signaling Technology) and Akt (11E7, 1:1000; Cell Signaling Technology) were used.

Cell culture and treatment. Primary mammary epithelial cells from Tip30mammary glands were cultured in mammary epithelial cell growth medium with growth factors, cytokines and supplements (Lonza, Allendale, NJ, USA) at $37^{\circ} \mathrm{C}$ in $5 \% \mathrm{CO}_{2}$ in an incubator for $24 \mathrm{~h}$, then treated with NVP-BEZ235 $(100 \mathrm{nM})$ or LY294002 $(50 \mathrm{nM})$ for $48 \mathrm{~h}$.

shRNAs. Short hairpin RNAs (shRNAs) were expressed in primary mammary cells using a lentiviral packaging system as described. ${ }^{25}$ Vectors encoding shRNA against mouse FoxA1 or control non-target shRNAs were purchased from Thermo Scientific Dharmacon RNAi Technologies (Pittsburgh, PA, USA). The procedures used to produce retroviruses and to infect target cells were as described previously. ${ }^{25}$

Gene expression analysis. Gene expression data was generated using Affymetrix mouse genome 430A 2.0 gene chips and will be available at the GEO at NCBI (USA). Unsupervised hierarchical clustering was conducted using Cluster 3.0 and results were viewed using Java Tree View (Free Software Foundation Inc., Boston, MA, USA software). Ras and EGFR pathway predictions were conducted as previously described ${ }^{48}$ Gene set enrichment analysis was conducted as described ${ }^{49}$ using a gene set derived from genes that are upregulated in luminal progenitor cells. ${ }^{30}$
Statistics. Results were represented as mean \pm S.E.M. or \pm S.D. as indicated. Statistical significance was assessed with a two-tailed, unpaired $t$-test. Tumor-free curves were compared using a log-rank (Mantel-Cox) test. Tumor incidences were evaluated with a $\chi^{2}$-test.

\section{Conflict of Interest}

The authors declare no conflict of interest.

Acknowledgements. We are grateful to Jill Pecha for backcrossing Tip30 knockout gene into Balb/c mice and Ying Qin for histological examination of preneoplastic lesions and tumors. This work was supported by NIDDK grant DK066110-01 and DOD grant W81XWH-08-1-0377 to $\mathrm{H}$ Xiao, Komen grant $\mathrm{KG} 110510$ and $\mathrm{NCl}$ grant 1R01CA160514-01A1 to E Andrechek and Guangdong Natural Science Foundation grant (10151051501000050) to A Li F Chen and A Li were supported in part by fellowships from Nanfang Hospital, China. M Williams was supported by NIH 5T32GM92715 training grant. CY was supported by National Institute of Health (1R01ES017777-01A1).

1. Bocchinfuso WP, Korach KS. Mammary gland development and tumorigenesis in estrogen receptor knockout mice. J Mammary Gland Biol Neoplasia 1997; 2: 323-334.

2. Anderson $E$. The role of oestrogen and progesterone receptors in human mammary development and tumorigenesis. Breast Cancer Res 2002; 4: 197-201.

3. Allred DC, Brown P, Medina D. The origins of estrogen receptor alpha-positive and estrogen receptor alpha-negative human breast cancer. Breast Cancer Res 2004; 6 : 240-245.

4. Shackleton M, Vaillant F, Simpson KJ, Stingl J, Smyth GK, Asselin-Labat ML et al. Generation of a functional mammary gland from a single stem cell. Nature 2006; 439: 84-88.

5. Stingl J. Estrogen and progesterone in normal mammary gland development and in cancer. Horm Cancer 2011; 2: 85-90.

6. Stingl J, Raouf A, Eirew P, Eaves CJ. Deciphering the mammary epithelial cell hierarchy. Cell Cycle 2006; 5: 1519-1522.

7. Villadsen R, Fridriksdottir AJ, Ronnov-Jessen L, Gudjonsson T, Rank F, LaBarge MA et al. Evidence for a stem cell hierarchy in the adult human breast. J Cell Biol 2007; 177: 87-101.

8. Booth BW, Smith GH. Estrogen receptor-alpha and progesterone receptor are expressed in label-retaining mammary epithelial cells that divide asymmetrically and retain their template DNA strands. Breast Cancer Res 2006; 8: R49.

9. Shyamala G, Chou YC, Cardiff RD, Vargis E. Effect of c-neu/ ErbB2 expression levels on estrogen receptor alpha-dependent proliferation in mammary epithelial cells: implications for breast cancer biology. Cancer Res 2006; 66: 10391-10398.

10. Shehata M, Teschendorff A, Sharp G, Novcic N, Russell IA, Avril S et al. Phenotypic and functional characterisation of the luminal cell hierarchy of the mammary gland. Breast Cancer Res 2012; 14: R134.

11. Liu BY, McDermott SP, Khwaja SS, Alexander CM. The transforming activity of Wnt effectors correlates with their ability to induce the accumulation of mammary progenitor cells. Proc Natl Acad Sci USA 2004; 101: 4158-4163.

12. Li Y, Welm B, Podsypanina K, Huang S, Chamorro M, Zhang $X$ et al. Evidence that transgenes encoding components of the Wnt signaling pathway preferentially induce mammary cancers from progenitor cells. Proc Natl Acad Sci USA 2003; 100 15853-15858.

13. Oakes SR, Naylor MJ, Asselin-Labat ML, Blazek KD, Gardiner-Garden M, Hilton HN et al. The Ets transcription factor Elt5 specifies mammary alveolar cell fate. Genes Dev 2008; 22: 581-586.

14. Vaillant F, Asselin-Labat ML, Shackleton M, Forrest NC, Lindeman GJ, Visvader JE. The mammary progenitor marker $\mathrm{CD} 61 /$ beta3 integrin identifies cancer stem cells in mouse models of mammary tumorigenesis. Cancer Res 2008; 68: 7711-7717.

15. Jeselsohn R, Brown NE, Arendt L, Klebba I, Hu MG, Kuperwasser C et al. Cyclin D1 kinase activity is required for the self-renewal of mammary stem and progenitor cells that are targets of MMTV-ErbB2 tumorigenesis. Cancer Cell 2010; 17: 65-76.

16. Henry MD, Triplett AA, Oh KB, Smith GH, Wagner KU. Parity-induced mammary epithelial cells facilitate tumorigenesis in MMTV-neu transgenic mice. Oncogene 2004; 23 6980-6985.

17. Molyneux G, Geyer FC, Magnay FA, McCarthy A, Kendrick H, Natrajan R et al. BRCA1 basal-like breast cancers originate from luminal epithelial progenitors and not from basal stem cells. Cell Stem Cell 2010; 7: 403-417.

18. Xiao H, Tao Y, Greenblatt J, Roeder RG. A cofactor, TIP30, specifically enhances HIV-1 Tat-activated transcription. Proc Natl Acad Sci USA 1998; 95: 2146-2151.

19. Shtivelman E. A link between metastasis and resistance to apoptosis of variant small cell lung carcinoma. Oncogene 1997; 14: 2167-2173.

20. Ito M, Jiang C, Krumm K, Zhang X, Pecha J, Zhao J et al. TIP30 deficiency increases susceptibility to tumorigenesis. Cancer Res 2003; 63: 8763-8767. 
21. Tong X, Li K, Luo Z, Lu B, Liu X, Wang T et al. Decreased TIP30 expression promotes tumor metastasis in lung cancer. Am J Pathol 2009; 174: 1931-1939.

22. Zhao J, Ni H, Ma Y, Dong L, Dai J, Zhao F et al. TIP30/CC3 expression in breast carcinoma: relation to metastasis, clinicopathologic parameters, and P53 expression. Hum Pathol 2007; 38: 293-298.

23. Jiang C, Ito M, Piening V, Bruck K, Roeder RG, Xiao H. TIP30 interacts with an estrogen receptor alpha-interacting coactivator $\mathrm{CIA}$ and regulates c-myc transcription. $\mathrm{J}$ Biol Chem 2004; 279: 27781-27789.

24. Zhang C, Mori M, Gao S, Li A, Hoshino I, Aupperlee MD et al. Tip30 deletion in MMTV-Neu mice leads to enhanced EGFR signaling and development of estrogen receptor-positive and progesterone receptor-negative mammary tumors. Cancer Res 2010; 70: 10224-10233.

25. Zhang C, Li A, Zhang X, Xiao H. A novel TIP30 protein complex regulates EGF receptor signaling and endocytic degradation. J Biol Chem 2011; 286: 9373-9381.

26. King FW, Shtivelman E. Inhibition of nuclear import by the proapoptotic protein CC3. Mol Cell Biol 2004; 24: 7091-7101.

27. Pecha J, Ankrapp D, Jiang C, Tang W, Hoshino I, Bruck K et al. Deletion of Tip30 leads to rapid immortalization of murine mammary epithelial cells and ductal hyperplasia in the mammary gland. Oncogene 2007; 26: 7423-7431.

28. Perou CM, Sorlie T, Eisen MB, van de Rijn M, Jeffrey SS, Rees CA et al. Molecular portraits of human breast tumours. Nature 2000; 406: 747-752.

29. Vargo-Gogola T, Rosen JM. Modelling breast cancer: one size does not fit all. Nature Rev Cancer 2007; 7: 659-672.

30. Lim E, Wu D, Pal B, Bouras T, Asselin-Labat ML, Vaillant F et al. Transcriptome analyses of mouse and human mammary cell subpopulations reveal multiple conserved genes and pathways. Breast Cancer Res 2010; 12: R21.

31. Liu S, Ginestier C, Charafe-Jauffret E, Foco H, Kleer CG, Merajver SD et al. BRCA1 regulates human mammary stem/progenitor cell fate. Proc Natl Acad Sci USA 2008; 105 : $1680-1685$

32. Li W, Ferguson BJ, Khaled WT, Tevendale M, Stingl J, Poli V et al. PML depletion disrupts normal mammary gland development and skews the composition of the mammary luminal cell progenitor pool. Proc Natl Acad Sci USA. 2009; 106: 4725-4730.

33. Sleeman KE, Kendrick $H$, Robertson D, Isacke CM, Ashworth A, Smalley MJ. Dissociation of estrogen receptor expression and in vivo stem cell activity in the mammary gland. J Cell Biol 2007; 176: 19-26.

34. Lange CA, Shen T, Horwitz KB. Phosphorylation of human progesterone receptors at serine-294 by mitogen-activated protein kinase signals their degradation by the $26 \mathrm{~S}$ proteasome. Proc Natl Acad Sci USA 2000; 97: 1032-1037.

35. Daniel AR, Faivre EJ, Lange CA. Phosphorylation-dependent antagonism of sumoylation derepresses progesterone receptor action in breast cancer cells. Mol Endocrinol 2007; 21 2890-2906.

36. Bernardo GM, Lozada KL, Miedler JD, Harburg G, Hewitt SC, Mosley JD et al. FOXA1 is an essential determinant of ERalpha expression and mammary ductal morphogenesis. Development 2010; 137: 2045-2054.

37. Liu S, Dontu G, Wicha MS. Mammary stem cells, self-renewal pathways, and carcinogenesis. Breast Cancer Res 2005; 7: 86-95.

38. Bernardo GM, Bebek G, Ginther CL, Sizemore ST, Lozada KL, Miedler JD et al. FOXA represses the molecular phenotype of basal breast cancer cells. Oncogene 2013; 32: 554-563.
39. Bernardo GM, Keri RA. FOXA1: a transcription factor with parallel functions in development and cancer. Biosci Rep 2012; 32: 113-130.

40. Wolf I, Bose S, Williamson EA, Miller CW, Karlan BY, Koeffler HP. FOXA1: Growth inhibitor and a favorable prognostic factor in human breast cancer. Int J Cancer 2007; 120: 1013-1022.

41. Russo J, Ao X, Grill C, Russo IH. Pattern of distribution of cells positive for estrogen receptor alpha and progesterone receptor in relation to proliferating cells in the mammary gland. Breast Cancer Res Treat 1999; 53: 217-227.

42. Clarke RB, Howell A, Potten CS, Anderson E. Dissociation between steroid receptor expression and cell proliferation in the human breast. Cancer Res 1997; 57: 4987-4991.

43. Shoker BS, Jarvis C, Clarke RB, Anderson E, Hewlett J, Davies MP et al. Estrogen receptor-positive proliferating cells in the normal and precancerous breast. Am J Pathol 1999; 155: 1811-1815.

44. Chan SR, Vermi W, Luo J, Lucini L, Rickert C, Fowler AM et al. STAT1-deficient mice spontaneously develop estrogen receptor alpha-positive luminal mammary carcinomas. Breast Cancer Res 2012; 14: R16.

45. Pei XH, Bai F, Smith MD, Usary J, Fan C, Pai SY et al. CDK inhibitor p18(INK4C) is a downstream target of GATA3 and restrains mammary luminal progenitor cell proliferation and tumorigenesis. Cancer Cell 2009; 15: 389-401.

46. Li A, Zhang C, Gao S, Chen F, Yang C, Luo R et al. TIP30 loss enhances cytoplasmic and nuclear EGFR signaling and promotes lung adenocarcinogenesis in mice. Oncogene 2012; 32: 2273-2281.

47. Sleeman KE, Kendrick H, Ashworth A, Isacke CM, Smalley MJ. CD24 staining of mouse mammary gland cells defines luminal epithelial, myoepithelial/basal and non-epithelial cells. Breast Cancer Res 2006; 8: R7.

48. Gatza ML, Lucas JE, Barry WT, Kim JW, Wang Q, Crawford MD et al. A pathway-based classification of human breast cancer. Proc Natl Acad Sci USA 2010; 107: 6994-6999.

49. Subramanian A, Tamayo P, Mootha VK, Mukherjee S, Ebert BL, Gillette MA et al. Gene set enrichment analysis: a knowledge-based approach for interpreting genome-wide expression profiles. Proc Natl Acad Sci USA 2005; 102: $15545-15550$

(c) (1) (2) Cell Death and Disease is an open-access journal published by Nature Publishing Group. This work is licensed under a Creative Commons Attribution-NonCommercialShareAlike 3.0 Unported License. The images or other third party material in this article are included in the article's Creative Commons license, unless indicated otherwise in the credit line; if the material is not included under the Creative Commons license, users will need to obtain permission from the license holder to reproduce the material. To view a copy of this license, visit http://creativecommons.org/licenses/ by-nc-sa/3.0/

Supplementary Information accompanies this paper on Cell Death and Disease website (http://www.nature.com/cddis) 